\title{
Attendance Connect —A Complete Mobile Attendance Governing using Face Recognition
}

\author{
Neel Makhecha
}

\begin{abstract}
Attendance Connect aims in simplifying the task of registering attendance in the class by teachers, managing attendance records and letting students access those up-to-date attendance records anytime. These fundamental goals of simplifying workflow of teachers and students is made possible through the use of advanced technologies like state-of-the-art group based face recognition and attendance code right from the mobile device. Moreover, Attendance Connect also features additional functionalities like Schedules to make it easier for marking attendance of sessions, prior knowledge of sessions to attend or miss and Announcement Posts which lets teachers post announcements about changes in class schedules, homework or pretty much anything to stay in touch with the students. This is achieved with incredibly easy-to-use user interface developed for iOS devices using Swift and Objective- $C$ with a modern backend of Firebase. In addition to that, the hardware requirement of Attendance connect is limited only to compatible mobile devices like smartphones or tablets. Meaning, it is easy to install, easy to start using and is significantly affordable.
\end{abstract}

Keywords: attendance governing system, iOS Application, group face recognition, mobile application.

\section{INTRODUCTION}

Attendance governing is one of the most important aspects of any educational institution to consider. For teachers, it's important to keep the track of every student's attendance to maintain discipline. For students, it helps to keep a track about their classes and keep up with the criteria of institution. Various institutions need attendance governing systems for various reasons like enhancing the speed and accuracy of registering the attendance, automatic report generation, enhancing punctuality of staff and students, alerts to parents/students if needed and more [1]. These days, to achieve this, various schools, colleges, universities and tuition classes adopt digital or smart attendance governing systems. This may include manually entering attendance records regularly (everyday or every week) or through automated authentication like biometrics authentication (viz. fingerprint recognition, face recognition, etc.). There has been many attendance governing systems developed in the history attempting to make attendance governing simple, easy to install, use and are affordable. The attendance governing systems developed which uses cutting-edge technologies like biometrics authentication (viz. fingerprint authentication, face authentication, etc.) demands significant additional hardware requirements and may also require customisations as per organisation or customer needs.

Revised Manuscript Received on February 15, 2020.

* Correspondence Author

Neel Makhecha*, Undergraduate Computer Engineering student, Charotar University of Science and Technology (CHARUSAT), Gujarat (India).

(C) The Authors. Published by Blue Eyes Intelligence Engineering and Sciences Publication (BEIESP). This is an open access article under the CC BY-NC-ND license (http://creativecommons.org/licenses/by-nc-nd/4.0/)

This not only raises the cost of implementing such attendance governing system in practice but also makes it complicated for small institutions and organisation to adapt it quickly.

The goal of developing Attendance Connect ultimately comes down to solve these problems. An attendance governing system that's incredibly easy to install and use, significantly affordable and portable and featuring much advanced technologies than manually recording entries. This is achieved by developing a mobile application with a user interface design that's easy to use by anyone (teachers or students), storing attendance records over the cloud with modern backend (viz. Firebase) to access data from anywhere and from any device easily, implementing cuttingedge, state-of-the-art AI technologies like group face recognition and a unique alternative way of registering attendance, Attendance Code.

\section{LITERATURE REVIEW:}

In this section, the research works and development from various researchers and developers carried out is reviewed which is related to the proposed model. Some of these works achieves the goals of simplifying attendance management by introducing it into mobile devices thereby also making an affordable solution; while the others have achieved simplifying it by using modern technologies but it raises costs of installation and maintenance significantly.

Dr. D. Asir Antony Gnana Singh et al published a paper on a 'Mobile Application for Student Attendance and Mark Management System'. The application presented was mainly designed for the faculties and other staff members of the organization who maintain attendance and marks regularly. The application proposed there uses manual method of marking the attendance on a mobile phone. [2]

A review article from KarwanJacksi from University of Zakho (Iraq) et al, presents a web-based attendance management system using Laravel Framework, Javascript and MySQL Database. The system features a full-fledged attendance management system with multiple users which can be implemented at the organisation level even for centralised attendance management. [3]

In 'Smart Attendance Management System (SAMS)' by RasikaNaik et al an attendance management system using fingerprint recognition is proposed. Here, they incorporated portability by introducing wireless communications among the fingerprint sensor and the computer. Here the idea is, the teacher will bring a handheld device in the class and will hand it over to students. Students will mark their attendance turn by turn which will mark the attendance. As mentioned earlier, this method uses advanced technologies rather than manually inputting the attendance. 
But it comes with a drawbacks that a computer needs to be reserved to work as a server for the device, a special handheld device is required to purchase and then there's a software installation involved on the dedicated computer. This may increase the cost of adopting (and using) such attendance governing system which might not be affordable to small institutions or organisations. [4]

'Automated Student Attendance Management System using Face Recognition' by GodswillOfualagba et al presented a system which uses an IP camera mounted in front of the classroom to take the images and perform face recognition to register students' attendance. This system requires significantly less manual work but comes at the cost of additional hardware installations. However, as it is built using open source image processing library, it mentions that is not dependent on vendor specific hardware or software, which may cut the costs down depending on the requirements. [5]

Hence from the literature review, it is observed that there's been various attendance governing systems developed as per different requirements to simplify the process of managing attendance in educational institutions by adopting various technologies and to fill the gaps either by considering portability and affordability of system in high priorities or by considering ease of use and adopting cutting-edge technologies even with multiple additional hardware dedicated to work with the system. However, this paper presents Attendance Connect which is an attempt to fill both the gaps, that is, portability and affordability is at the high priority but at the same time adopting the advanced technologies like face recognition and other custom methods of registering attendance to ensure ease of use.

\section{BACKGROUND}

\section{A. Registering Attendance of Multiple Students:}

Most traditional attendance governing system either involved registering of attendance manually by the teacher or each student registering their attendance on a device turnby-turn. This generally takes up significant time when the number of students are large in numbers. That's why there is a need of a system which can register attendance of multiple students at once to save time and efforts.

\section{B. Face Recognition on Mobile Devices:}

There has been a significant research and development done in face recognition on mobile devices. One of the shortcomings to perform face recognition on mobile devices is its limited hardware support. The CPUs and GPUs are built with efficiency in mind and are generally not as powerful as a desktop/laptop setups. Hence, tradeoff has to be made in terms of accuracy and computational complexity just to implement it on a low powered mobile device. Prior to perform face recognition, there is a need to perform face detection. It could be possible that in an image there are multiple faces. Now to run the face recognition algorithm on all those detected faces can cause significant overhead. That's why most mobile devices implement on-device face recognition just for the simple authentication purposes like unlocking the phone, signing in, et cetera which require single face on a given image.

Another approach to solve this problem of performing computationally intensive task with maximum accuracy is to perform it on a server. Hence, performing face recognition can be a great option if it needs to be done with greater accuracy and high performance. There have been various ways by which this can be achieved, like training a machine learning model to recognise faces and run it on a reliable remote server. Another way is to use services that uses stateof-the-art face recognition algorithms and are much reliable in terms of speed performance and accuracy. These services either provides special SDKs to communicate with their cloud platform from the mobile devices or requires to perform HTTP requests which responds with the result of accuracy, confidence of match and other properties detected from the image. The only drawback of using this it needs to be connected with internet whenever face recognition needs to be performed. Moreover, as it sends the whole image to the server, it also requires fast internet connection (greater bandwidth). Otherwise, it may result in significantly slow performance.

\section{METHODOLOGIES:}

\section{A. Architectures:}

\section{Basic App Flow:}

The app is designed to make it easy for teachers to register, sign-in, create classes, generate Class IDs to let students enrol, schedule the classes and more. The same app can be used for students as well to enrol to classes, check the scheduled sessions, check announcement posts, register their attendance using Attendance Code or QR code, etc. On logging in, the app will present the appropriate user interface and options as per whether the user is a student or teacher.

All these features are presented along a simple tabbed layout of the app which can be visualised as shown in Figure

\section{Client-Server Architecture:}

Attendance Connect uses modern and powerful backend from Firebase for logging in and storing all users' data. Attendance Connect uses backend of Kairos to implement the face recognition technology, hence all the enrolled images along with performing face recognition is done on the Kairos servers. As it stores all information on the cloud, it becomes very easy to access it and use the app from any device just by singing in.

Figure 2 shows the basic client-server architecture 


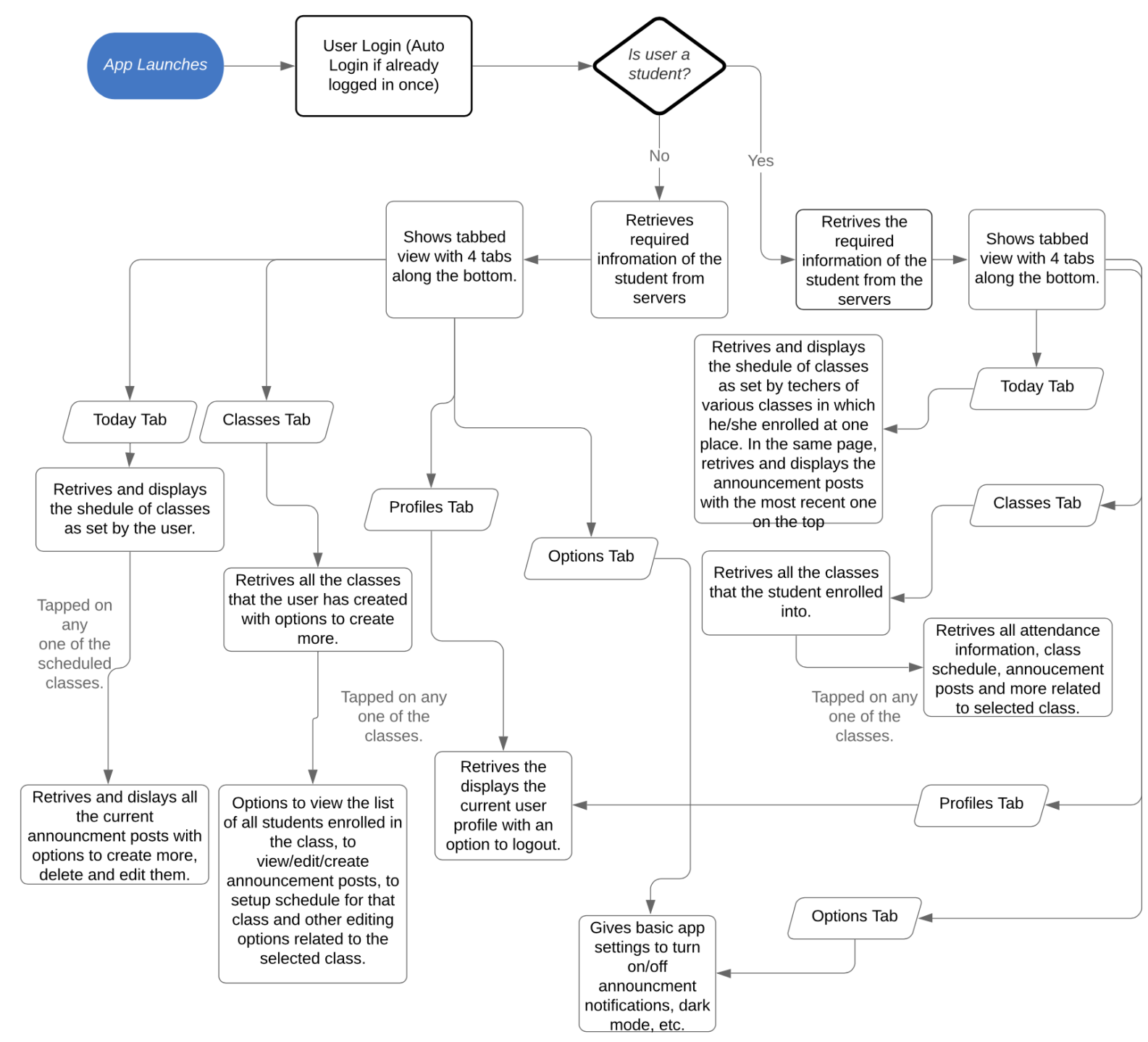

Figure 1: Visual representation for basic flow of the app when launched normally

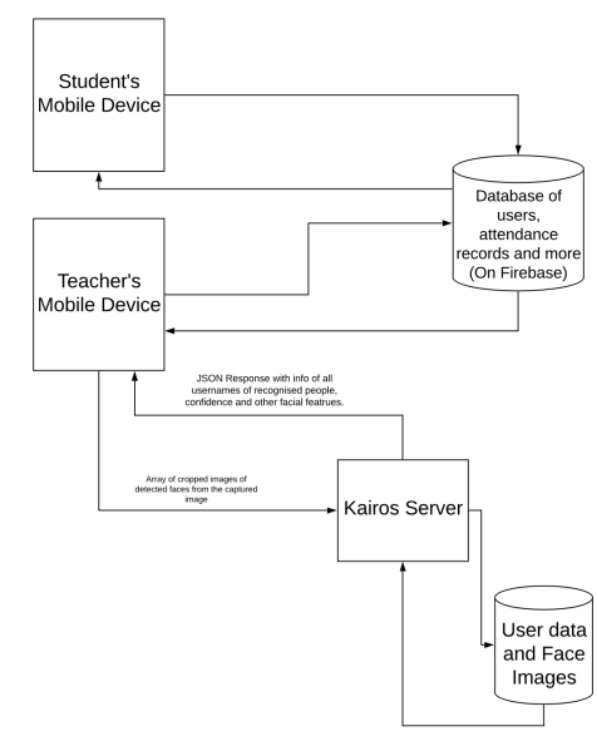

Figure 2: Visual representation of client-server architecture.

Retrieval Number: C4747029320/2020@BEIESP DOI: 10.35940/ijeat.C4747.029320 Journal Website: www.ijeat.org
Published By:

420 Blue Eyes Intelligence Engineering \& Sciences Publication 


\section{B. Functionalities:}

\section{Multiple Attendance Registering Techniques:}

\section{(a) Using Attendance Code:}

The goal of this app is to create a system that delivers a superior methods of registering attendance than the manual marking of attendance for individual students by teachers. One of the ways is to have some method where students can mark their own attendance. But the challenges with that is to ensure whether the student who is marking attendance is actually him (i.e. to verify the identity of the student) and one student cannot mark attendance for multiple students by signing in with others credentials or using others mobile phone. Hence, this unique method of attendance code is developed.

\section{The process is as follows:}

Step 1: The teacher will generate a unique code from one of the pre-specified lengths, i.e. small, medium or large length.

Step 2: Once generated (which is instantaneous), the teacher will push 'Activate Code' button. This will activate the code, meaning students of that class can mark their attendance using that active code once from their devices.

Step 3: Teacher will announce the same code in the class and students will select particular teacher's class and enter the announced code on to their own device. This will mark their attendance for that session.

Step 4: The teacher will deactivate the code whenever he/she feels that everyone might have done with registering.

Note: The generated code will be alphanumeric and large enough to ensure that student can enter the code once at a time within the period of activation. Hence, it prevents proxy attendance of students to certain extent.

\section{(b) Using Face Recognition:}

In this method, instead of students marking their own attendance, teachers will register student's attendance. Marking attendance manually can be tedious task for teachers. Hence, face recognition on Attendance Connect will enable to mark attendance of multiple students at once. How this feature will work is described as below.

Teacher will open the app and will select the class for which he/she wants to register attendance. Upon selecting the option to take attendance using face recognition, a view finder will be presented with back camera turned on. It will have a few options which includes a switch to turn on/off flash or switch cameras between front/back (rarely to be used). The teacher can target a few (upto 8-10 students) at once and capture a photo. Once shutter button is tapped, Attendance Connect will process the image and show the list of all the recognised students to mark their attendance. The teacher will repeat the same simple process of capturing students' photographs until the whole class is covered.

This process is much better than either Attendance Code or manual method, as it saves significant amount of time. The students don't require to pay attention to their roll numbers being spoken while attendance nor they are required to enter Attendance Code to mark their own attendance. Teachers can do it even in between the session without disturbing the whole class. Moreover, it requires if the class is of 50 students, it takes around 6 photos to cover every student register attendance, which is a lot faster process.

\section{Face Recognition - Implementation:}

Attendance Connect uses combination of two APIs to deliver faster and accurate face recognition. How face recognition on Attendance Connect is performed is described as follows.

\section{Using Kairos cloud API for face recognition:}

Kairos is a service that enables businesses and developers to easily build face recognition into their software products using their cloud APIs [6]. The image once converted into a proper format and sent it to the server finds all the faces and matches them against pre-enrolled faces from Kairos database. It will in turn return a JSON response with various information on which faces are detected and what are the various features of individual detected faces viz. confidence of match, eyes opened/closed, etc(refer Figure 2). Kairos have provided some technical details on how to position the subject and what should be the dimensions for the most optimal outcome from the service. It is described as below.

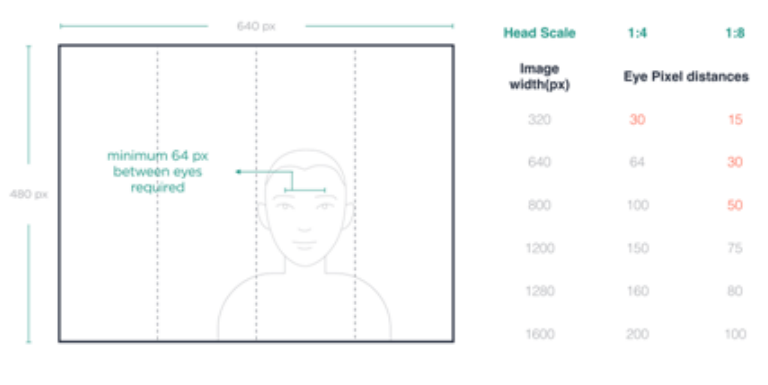

Figure 3: Approximate Image specification for optimal results [7]

Kairos have given various recommendations on capturing image for positioning expressions, focus and lighting. It is described as below [7]:

Positioning: Face the camera directly and position yourself so that your face fills the frame with 1-2 inch margins on each side. Try to avoid extreme angles and poses.

Expression: Maintain a neutral expression, remove any dark glasses or tinted lenses, and keep both eyes open.

Lighting: For increased visibility, avoid bright backlighting and glare by taking your photographs under even light.

Focus \& Movement: Image focus and blur can have similar effects on performance as low resolution - make sure your captured image is not blurry. 
Kairos accepts image with any resolution and without any restriction of other objects being included in the image. But this creates a problem of slow performance. Though Kairos is very fast in processing the image and responding with it, sending over such a high resolution image could be significantly slow, especially on a slower internet connections. Hence, Attendance Connect implements following approach of using another framework called Vision from Apple to make the process faster.

\section{Using Apple Vision Framework + Kairos for face recognition:}

Vision Framework can be used to apply computer vision algorithms to perform variety of tasks on input images and video. The Vision framework performs face and face landmark detection, text detection, barcode recognition, image registration, and general feature tracking. Vision also allows the use of custom Core ML models for tasks like classification or object detection. [7]

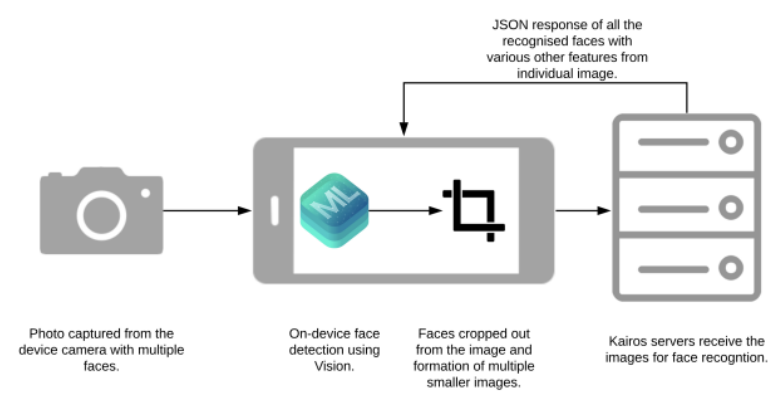

Figure 4: Face Recognition working using Apple Vision Framework + Kairos

Out of from all the varieties of purpose for which Vision can be used, our goal is to make the procedure of face recognition faster. That can be done if face detection (which is less computational intense than recognition) can be performed on-device with Vision. On performing face detection on a captured image with multiple faces, detected faces can be cropped out forming multiple smaller images. Only those smaller images are then sent to the Kairos sever to perform face recognition. Hence, this will result in a significant reduce in time delay. The amount of time taken (or time delay reduced) completely depends on the network speed over which the images are being sent. The following diagram depicts the whole procedure described above.

\section{Attendance Suggestions:}

Attendance Connect tracks your attendance records regularly and suggests students based on their attendance and attendance criteria how many sessions to attend next to keep up with the criteria or how many sessions it will be okay to miss without violating the criteria set by the teacher of the class.

To determine how many sessions are required to attend if one's attendance is less than the specified attendance limit criteria, following algorithm is used:

Let's suppose

$\mathrm{A}=$ current attendance of the student (in percentage, so range is $0 \leq A \leq 100$ )
$\mathrm{C}=$ minimum attendance limit criteria set by the teacher in percentage (where $0 \leq C \leq 100$ )

Then, $\mathrm{c}=\mathrm{C} / 100$ (where $0.0 \leq c \leq 1.0$ )

$\mathrm{T}=$ total sessions conducted

$\mathrm{P}=$ total sessions attended

$\mathrm{N} 1$ = number of sessions to attend

So, $\mathrm{A}=$ (total no. of sessions attended / total no. of sessions conducted) $* 100$

$\therefore A=\frac{P}{T} * 100$

If $\mathrm{A}>\mathrm{C}$,

Then,

$N^{\prime}=\frac{(c * T)-P}{1-c}$

$\mathrm{N} 1=\operatorname{ceil}\left(\mathrm{N}^{\prime}\right)$

To determine for how many sessions it will be fine to miss the sessions and still be within the attendance limit criteria, following algorithm is used:

Let's suppose, N2 = number of safe sessions

If $\mathrm{A}<\mathrm{C}$,

Then,

$N^{\prime}=\frac{P-c * T}{c}$

$\mathrm{N} 2$ = floor $\left(\mathrm{N}^{\prime}\right)$

As per the above results, a sentence is framed which is presented as a suggestion to the users (students). Statements are mentioned as below:

If A > C: "You have to attend next N1 sessions to reach the attendance criteria"

If A < C: "You haveN2 safe sessions that you can miss and still be within attendance criteria"

If A = C: "You should not miss the upcoming session"

\section{Announcement Posts:}

The feature of announcement posts on Attendance Connect complements the complete attendance governing system. It is useful to make small announcement that could be reminder of a homework submission, a material to refer prior to class, etc by the teachers. As Attendance Connect features scheduled classes, the complete time-table of the day is visible at a glance before the day. Hence, having such announcement related to the sessions right there makes it really easy and convenient to plan their day. 


\section{RESULTS}

\section{Comparative Analysis of different attendance systems:}

\begin{tabular}{|c|c|c|c|}
\hline $\begin{array}{l}\text { Feature } \\
\text { Description }\end{array}$ & $\begin{array}{l}\text { Traditional } \\
\text { Web Based } \\
\text { Attendance } \\
\text { Management } \\
\text { Systems }\end{array}$ & $\begin{array}{l}\text { Advanced } \\
\text { attendance } \\
\text { managers with } \\
\text { sophisticated } \\
\text { hardware }\end{array}$ & $\begin{array}{l}\text { Attendance } \\
\text { Connect }\end{array}$ \\
\hline $\begin{array}{l}\text { Requires a } \\
\text { dedicated } \\
\text { desktop/laptop } \\
\text { computer } \\
\text { system }\end{array}$ & Yes & Yes & No \\
\hline $\begin{array}{l}\text { Works on } \\
\text { mobile devices } \\
\text { like } \\
\text { smartphone or } \\
\text { tablets }\end{array}$ & Maybe & No & Yes \\
\hline $\begin{array}{l}\text { Uses advanced } \\
\text { technologies } \\
\text { like Face } \\
\text { Recognition to } \\
\text { simplify the } \\
\text { process of } \\
\text { marking } \\
\text { attendance }\end{array}$ & No & Yes & Yes \\
\hline $\begin{array}{l}\text { Additional } \\
\text { Hardware } \\
\text { Requirements }\end{array}$ & Maybe & Yes & No \\
\hline $\begin{array}{l}\text { Aprrox. Cost } \\
\text { of installation }\end{array}$ & Moderate & High & Low \\
\hline
\end{tabular}

Table 1: Comparison of different types of attendance management systems with Attendance Connect.

The given table (Table 1) shows the comparison of different types of attendance systems powering on different platforms and implementing different methodologies.

\section{Results for Attendance Suggestions:}

\begin{tabular}{|c|c|c|c|c|c|c|}
\hline $\begin{array}{l}\text { No } \\
\text {. }\end{array}$ & $\begin{array}{l}\text { Total no. } \\
\text { of sessions } \\
\text { conducted } \\
\text { (T) }\end{array}$ & $\begin{array}{l}\text { Total } \\
\text { no. of } \\
\text { session } \\
\text { s } \\
\text { attend } \\
\text { ed (P) }\end{array}$ & $\begin{array}{l}\text { Min, } \\
\text { attend } \\
\text { ance } \\
\text { limit } \\
\text { (in \%) } \\
\text { (C) }\end{array}$ & $\begin{array}{l}\text { Current } \\
\text { attendan } \\
\text { ce (in \%) } \\
\text { (A) }\end{array}$ & $\begin{array}{l}\text { No. Of } \\
\text { sessions } \\
\text { to } \\
\text { attend } \\
\text { (N1) }\end{array}$ & $\begin{array}{l}\text { No. Of } \\
\text { safe } \\
\text { sessions } \\
\text { (N2) }\end{array}$ \\
\hline 1 & 12 & 12 & $70 \%$ & $100 \%$ & 0 & 5 \\
\hline 2 & 12 & 9 & $70 \%$ & $75 \%$ & 0 & 0 \\
\hline 3 & 12 & 8 & $70 \%$ & $67 \%$ & 2 & 0 \\
\hline
\end{tabular}

Table 2: Example results of attendance suggestions for attending upcoming sessions based on current attendance.
Attendance suggestion is one of the most important features that students may rely on to decide when to miss the session when it's required without compromising with the attendance criteria for the subject. Hence, Table 2 shows detailed results for what situations of attendance, what would be the output that the student might get.

In Table 2, three examples are given where the total number of sessions conducted is 12 . The cases covered are such that when the attendance percentage is higher than the minimum criteria, another one with equal to the minimum criteria and the last one with attendance greater than minimum criteria. It shows the value of N1 and N2 (outputs) in all the respective cases.

\section{LIMITATIONS}

As Attendance Connect uses iPhone's built-in camera to capture the photos of multiple students at once, it may happen that the photo may not turn out to be clear. The potential reason could be shaking hands when taking photo or students looking away and the software fails to detect faces. Because of that, the teacher still have an option to mark attendance manually. Moreover, the photos taken are saved on-device to later manually review those images and mark the attendance and can be deleted as per teacher's wish. Moreover, Attendance requires a high speed internet connection when registering attendance through face recognition to upload the images as soon as they are clicked and to process the same. This could be a problem when using this app in the area of slower internet connectivity. Face recognition can be brought offline to overcome this limitations, but due to limited processing capabilities of ondevice chipsets, this could not be possible on consumer devices yet.

\section{TOOLS \& TECHNOLOGIES}

Programming Language: Swift 4 and Objective-C.

IDE used: Xcode 10 on macOS 10.14 Mojave.

Key frameworks and APIs: UIKit, AVFoundation, Firebase, AlamoFire, SwiftyJSON.

Other Technologies used: Kairos Cloud Platform

System Requirements (Software): Apple iOS 10.3 or later.

System Requirements (Hardware): Apple iPhone 5 or later, iPod touch (6th gen.) or later, iPad (4th gen.) or later, iPad mini 2 or later, iPad Air (all generations), iPad Pro (all generations)

Other Requirements: Requires active internet connection.
Retrieval Number: C4747029320 /2020@BEIESP
Published By: 
VIII. SCREENSHOTS

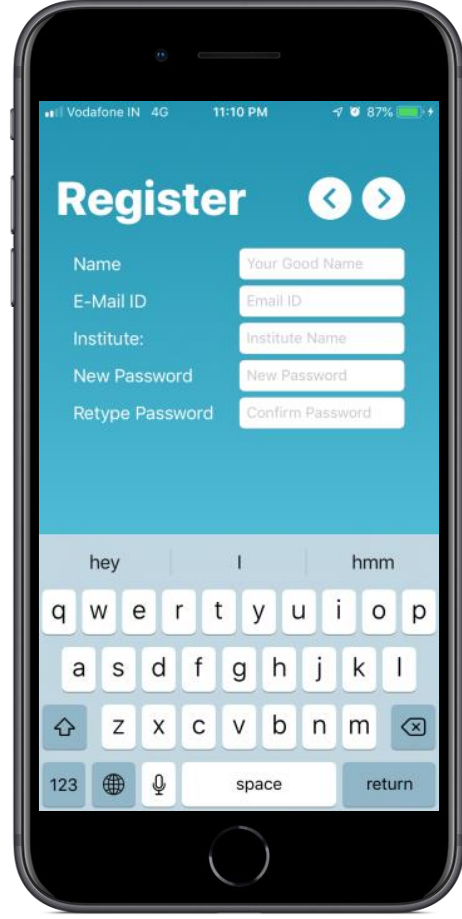

Figure 5: Attendance Connect Registration form for teachers.

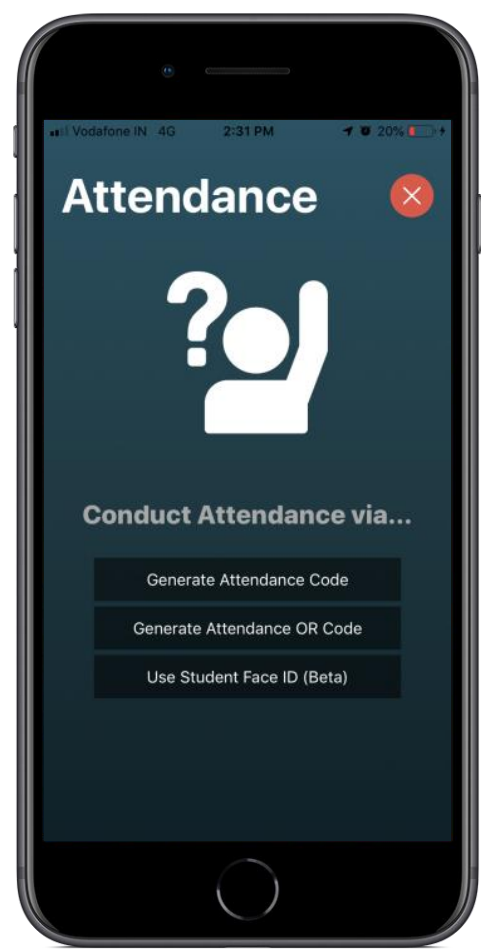

Figure 8: Attendance options for teachers to take attendance with.

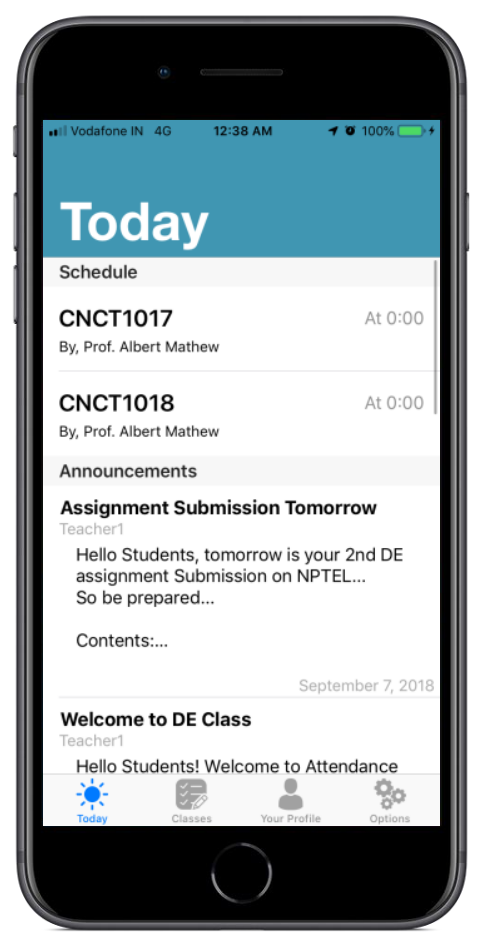

Figure 6: Today tab for students.

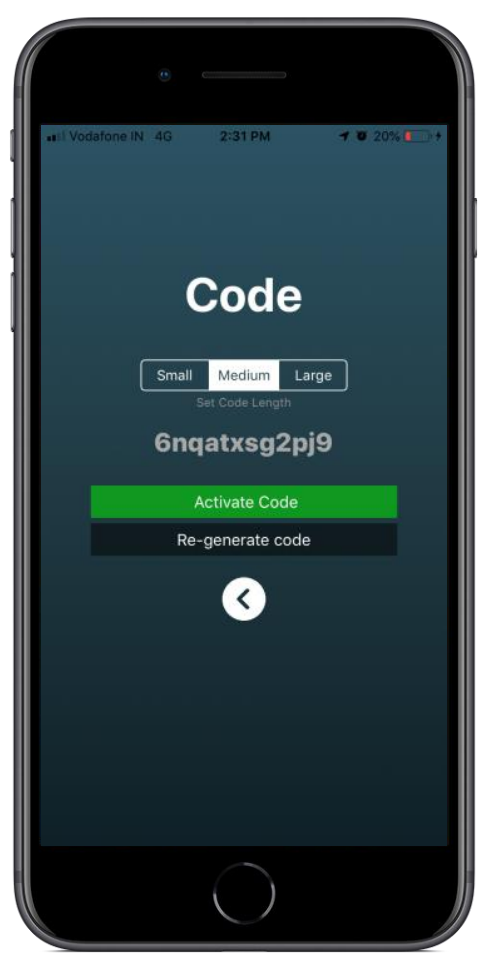

Figure 9: When taking attendance using Attendance Code

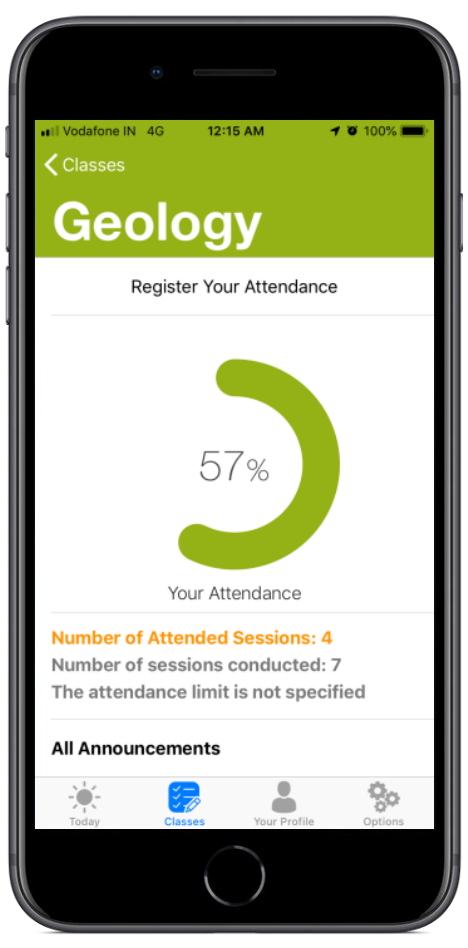

Figure 7: Expanding subjects to detailed view (student signed in)

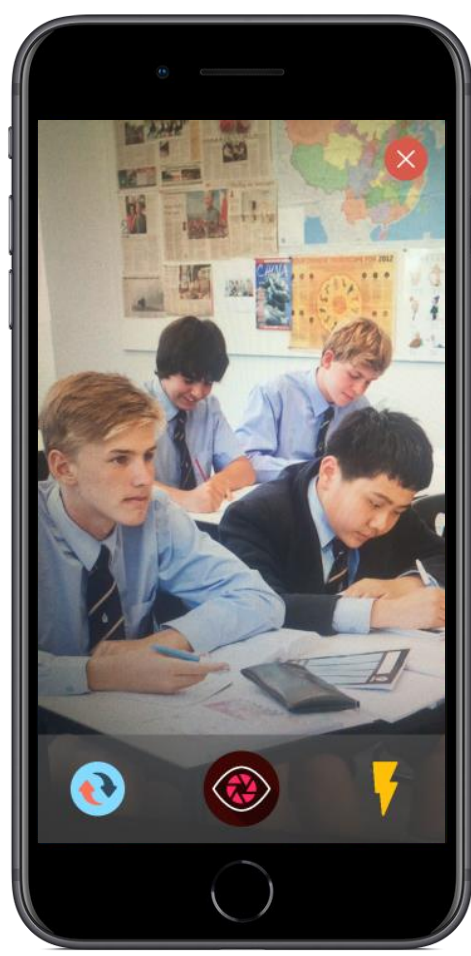

Figure 10: Taking attendance using face recognition

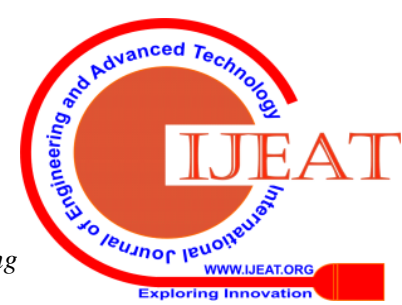




\section{CONCLUSION}

This paper presented an attendance governing (management) system, called Attendance Connect that uses advanced and unique technologies to register student attendance like face recognition and attendance code. It also have some additional useful features like attendance suggestions, announcement posts, schedule and more which complements the entire experience of attendance governing. Moreover, Attendance Connect don't require any additional hardware installations or requirements, other than a compatible mobile device, which makes it a much affordable attendance governing system for anyone. Hence Attendance Connect is easy-to-use, affordable and can be easily adopted by large or small educational institutions.

\section{REFERENCES}

1. Article on 'Why does your institute need an attendance management system' at https://fedena.com/blog/2018/06/why-does-your-instituteneed-an-attendance-management-system.html.

2. Dr. D. Asir Antony Gnana Singh, Dr. E. JebamalarLeavline, P. MeeraVijayan (2017), 'Mobile Application for Student Attendance and Mark Management', International Journal of Computational Intelligence Research, ISSN 0973-1873 Volume 13, Number 3 (2017), pp. 425-432.

3. Jacksi, Karwan\& Ibrahim, Falah\&Zebari, Shahab. (2018). Student Attendance Management System. International Journal of Engineering and Technology. 6. 49-53. 10.21276/sjet.2018.6.2.1.

4. "SMART ATTENDANCE MANAGEMENT SYSTEM (SAMS)", International Journal of Emerging Technologies and Innovative Research (www.jetir.org | UGC and issn Approved), ISSN:23495162, Vol.3, Issue 2, page no. pp47-50, February-2016, Available at : http://www.jetir.org/papers/JETIR1602010.pdf

5. Ofualagba, Godswill\&Osas, Omijie\&Orobor, Ise\&Oseikhuemen, Ibhadode\&Etse, Odiete. (2018). Automated Student Attendance Management System Using Face Recognition. 5. 31-37.

6. 'Why Kairos' page titled as 'What is Kairos?' at www.kairos.com/features.

7. Recommendations and best-practices on Image Capture and Face Enrolment from Kairos, https://www.kairos.com/docs/api/bestpractices.

8. Developer Documentation on Vision Framework by Apple. Available at https://developer.apple.com/documentation/vision.

\section{AUTHOR'S PROFILE}

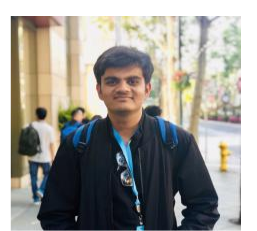

Neel Makhecha, is an undergraduate Computer Engineering student at Charotar University of Science and Technology (CHARUSAT), Gujarat (India). He is an Apple Developer and Android app developer having developed various successful apps for iOS, Android and macOS platforms. He has been one of the top 125 students in the world to win Apple's WWDC19 Scholarship. He is a lead graphics designer at Developer Students Club, CHARUSAT. He has also been awarded Layer Designing Conference 2019 Scholarship at San José, California (USA).

Mailto: neel.makhecha@gmail.com 